\title{
62. Somatik deyim olan 'kalp' sözcüğünün Rusça ve Türkçe karşılaştırmalı analizi
}

\section{Jale COȘKUN ${ }^{1}$}

\begin{abstract}
APA: Coşkun, J. (2021). Somatik deyim olan 'kalp' sözcüğünün Rusça ve Türkçe karşılaştırmalı analizi. RumeliDE Dil ve Edebiyat Araştırmaları Dergisi, (23), 976-985. DOI: 10.29000/rumelide.949950.
\end{abstract}

\section{$\ddot{O} \mathbf{z}$}

Deyimler dil içinde önemli bir yere sahiptir. Az sözle çok şey anlatabilmek ve anlatımı güçlendirmek açısından deyimler son derece önemlidir. Halkların belirli yaşam deneyimleri sonucunda ortaya çıkmış, halk arasında yaşatılan değerli hazinelerdir. Vücut organlarının isimlerini esas alan deyimlere, dilbilimde somatik deyimler denilmektedir. Somatik deyimler arasında 'kalp' sözcüğü de bulunmaktadır. Türkiye Türkçesinde 'kalp' olarak söylenen sözcük Rusçada 'serdtse' olarak adlandırılmaktadır. Bu çalışmada Rusça ve Türkçede 'kalp' sözcüğüyle oluşturulan deyimler incelenmiştir. Her iki dilde de ortak ya da benzer olan deyimlerin olduğu görülmüştür. Deyimlerin anlamları verilerek gerekli açıklamalar yapılmıştır. Çalışmamızda deyimin içeriğinden ve özelliklerinden söz edilerek belli başlı sözlükler taranmış, 'serdtse' (kalp) sözcüğünü içeren Rusça ve Türkçe bazı deyimler anlambilim (semantik) açısından incelenmiştir. İncelememiz, anlam bakımından örtüşen ve aynı tipte kurulan deyimler, anlam bakımından özdeş olan, fakat farklı bir tipte kurulan deyimler, benzerlik ve eşdeğerliği bulunmayan genel bir anlama sahip olan deyimler şeklinde kategorize edilmiştir. Bu çalışmayla, kültürlerarası farklılıklardan dolayı öğrencilerin zorluk çektikleri deyim çeviri sorununu aşmada yardımcı olmak ve anadili Türkçe olup Rusça öğrenen öğrencilere, incelenen deyimleri daha iyi anlama ve yerinde kullanma becerisi kazandırmak amaçlanmıştır. Ayrıca incelemiş olduğumuz bu deyimler, ilerde hazırlanacak olan herhangi bir deyimler sözlüğüne dâhil edilerek katkı sağlayabilecektir.

Anahtar kelimeler: Dilbilim, somatik deyimler, karşılaştırmalı analiz, Türkçe, Rusça

\section{A comparative analysis of the word 'heart' as a somatic idiom in Russian and Turkish}

\begin{abstract}
Idioms have a significant role in language. Idioms are important in terms of expressing many things with few words and strengthening the meaning. They are precious treasures emerged from people's certain life experiences and kept alive among people. Idioms based on the names of organs are called somatic idioms in linguistics. Somatic idioms also include the word 'heart'. The word 'kalp' (heart) in Turkey Turkish is called 'serdtse' in Russian. This study scrutinizes the expressions created with the word 'heart' in Russian and Turkish. It is observed that there are common or similar expressions in both languages. Necessary explanations are made by giving the meanings of the idioms. In this study, the content and features of idioms are discussed, certain dictionaries have been scanned, and some Russian and Turkish idioms containing the word 'serdtse' (heart) have been examined in terms of semantics. The analysis categorizes the idioms as idioms that overlap in
\end{abstract}

Dr. Öğr. Üyesi, İstanbul Aydın Üniversitesi, Yabancı Diller Yüksekokulu, Mütercim Tercümanlık Rusça Bölümü, jalezaman@aydin.edu.tr, ORCID ID: 0ooo-0003-2013-119o [Araştırma makalesi, Makale kayıt tarihi: 20.02.2021-kabul tarihi: 20.06.2021; DOI: 10.29000/rumelide.949950]

Adres

RumeliDE Dil ve Edebiyat Araşttrmaları Dergisi Osmanağa Mahallesi, Mürver Çiçeği Sokak, No:14/8 Kadıköy - İSTANBUL / TÜRKIYE 34714 e-posta: editor@rumelide.com tel: +90 $5057958124,+902167730616$

\section{Address}

RumeliDE Journal of Language and Literature Studies

Osmanağa Mahallesi, Mürver Çiçeği Sokak, No:14/8

Kadıköy - ISTANBUL / TURKEY 34714

e-mail: editor@rumelide.com,

phone: +90 $5057958124,+902167730616$ 
terms of meaning and formed in the same structure, idioms that are identical in meaning but formed in different structures, and idioms that have a general meaning without a similarity or an equivalence. This study aims to help students overcome the problem of idiom translation due to intercultural differences, and also help students, who speak Turkish as their native language and are learning Russian, to better understand and use the idioms examined in this study. In addition, idioms that are analyzed here will be able to contribute to any idiom dictionary that will be prepared in the future.

Keywords: Linguistics, somatic idioms, comparative analysis, Turkish, Russian

\section{Giriş}

Bilgiyi iletmenin ve almanın ana unsuru olan dil, insanlar arasında en önemli iletişim aracıdır. Halkın maddi ve manevi değerleri olan kültürün var olmasında ve aktarılmasında dilin büyük rolü vardır. Dil, dünyanın bir aynasıdır, o, sadece gerçeği yansıtmakla kalmaz, aynı zamanda her dil millete özgü ve benzersiz olan dünyanın kendi resmini oluşturur. Ayrıca, dil insan için var olan ve insan aracılığıyla gerçekleştirilen bir olgudur. Bu nedenle dilin bileşenlerinde; anlambilim, sözcükbilim, yapıbilim ve sözdizimde milletin derin psikolojisi ve dünya görüşünde belirli bir dereceye kadar yansitılır.

"Dil, hangi şekle girerse girsin her zaman bir ulusun bireysel yaşamının ruhsal bir düzenlemesidir." (Humboldt,V.,1984: 72).

Bir milletin tarihi, coğrafyası, dini değer ölçüleri, folkloru, müziği, sanatı, edebiyatı, ilmi, dünya görüşü ve millet olmayı gerçekleştiren her türlü ortak değerleri yüzyılların süzgecinden süzüle süzüle kelimelerde sembolleşerek dil hazinesine akmaktadır (Barın, E.,2004: 19).

"Dil, kültürün zaman ve mekan boyutlarında aktarılmasını ve zenginleştirilmesini sağlayan temel mekanizmadır" (Güngör,N., 1991:214).

Bir dilin söz varlığının önemli bir kısmını oluşturan deyimler, kullanıldığı dilin birçok özelliğini ortaya koymasının yanında anadili olarak o dili kullananlar ve o dili öğrenenlerin bilmesi gereken sözlerdir ve bir dilin sözcük, dil bilgisi gibi diğer parçaları düzgün bir şekilde kavranmış olsa bile deyimler olmaksızın dil öğrenme ve bir dile egemen olma çabası yetersiz kalır (Aksan, D., 2015: 82).

İmgesel anlamlı dil öğelerinin bir türünü oluşturan deyimler, sunulan öğretim sürecinde anlambilimsel ve bilişsel özellikleri temel alınarak kavramlaştırılmıştır (Akkök, E. A.,2009:61).

Deyimler dilbilimin geniş alanı kapsamaktadır. Deyimlerin ulusal ve kültürel özellikleri, halk bilgeliğini, gelenekleri ,davranışları, duyguları ve zihniyeti canlı ve etkileyici bir şekilde yansıtması önemli bir olgudur.

“Genellikle gerçek anlamının dışında kullanılan, anlatımı daha güzel ve etkileyici yapan, toplum tarafından ortak olarak benimsenen kalıplaşmış sözlere deyim denir” (Hengirmen, M.,2007:7).

Ömer Asım Aksoy Atasözleri ve Deyimler Sözlüğü I’de deyimi “Bir kavramı, bir durumu, ya çekici bir anlatımla ya da özel bir yapı içinde belirten ve çoğunun gerçek anlamlarından ayrı bir anlamı bulunan kalıplaşmış sözcük topluluğu ya da tümce” biçiminde vermiştir (Aksoy, Ö.A.,1995: 38).

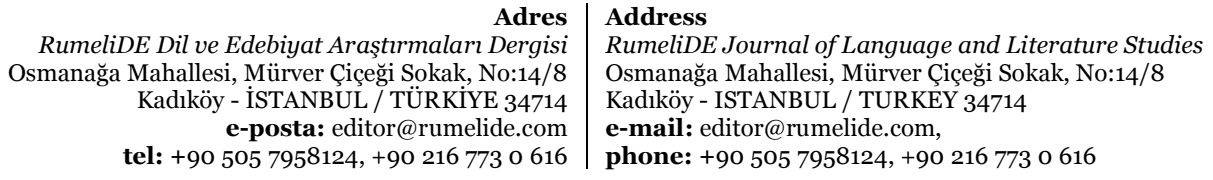

tel: $+905057958124,+902167730616$ 
Deyim, içeriği ve yapısı bakımından kalıplaşmış, bölünemeyen, anlamına göre bütünsel, ayrı bir sözcüğün anlamını taşıyan bir sözcük öbeği ya da cümlelere verilen genel addır. Deyimlerin orijinal kombinasyonun veya tek bir kelimenin yeni anlamının tekrardan yorumlanması ve oluşumu sürecinde ortaya çıan özel bir ikincil adlandırmanın ürünü olarak kabul edilmesi, deyimlerin ayırt edici bir özelliğidir.

Deyimler kullanıldıkları dile özgüdürler. Kullanıldıkları dilin dil bilgisi yapılarını, kelimelerini ve daha da önemlisi o dili anadili olarak kullananların kültürel yapılarına ait belirli özellikleri taşıdıkları için o dili tam olarak anlamanın temelini oluşturmaktadırlar (Dalak Erten, H.D., 2017:37).

Yasemin Çelik tarafından da ifade edildiği gibi genel olarak deyimler bir duyguyu, bir düşünceyi, bir durumu ya da bir kavramı gerçek anlamının dışında ya da gerçek anlamıyla etkili bir biçimde anlatan, en az iki sözcükten oluşan kalıp sözler biçiminde tanımlanabilir (Çelik,Y.,2017:74).

Deyimlerin dünyası çok büyüktür. Deyimler yüzyıllar boyunca insan varlığının ve eylemlerinin tüm alanlarını ve anlamsal açıdan o dili ana dil olarak konuşanların dünya görüşünü ortaya koyar. Deyimler; değerlendirme, tavsiye, kişiyi harekete geçirme, öneri, herhangi bir olgu ve eylemin kesinliği gibi özelliklere sahiptir.

Küreselleşme çağında nüfusun geniş kesimince yabancı dil öğrenmek, acil bir ihtiyaç olarak ortaya çıkmıştır. Ancak yabancı dil öğrenme süreci dildeki deyimsel ifadelerin varlığı gibi durumlarla zorlaşmaktadır. Bununla birlikte deyimler, konuşmayı zenginleştirir, imgesel, canlı ve çok yönlü hale getirir. Mecazi anlama sahip olan deyim, bir yandan dili çeşitlendirip ifadeyi daha anlamlı hale getirirken diğer yandan da konuşmayı kültürel özellikler açısından zenginleştirir.

\section{Amaç}

Çalışmamızın amacı, dil ve kültürlerarası iletişim bağlamında Rus ve Türk dillerinin sözcük düzeninde deyimsel alt yapının karşılaştırılabilir analizini oluşturmaktır.

$\mathrm{Bu}$ çalışmada, deyimsel birimlerin dil sistemi içerisindeki yerini ve önemini belirtmek amacıyla Türkçe'deki kalp ve onun Rusça'daki karşılığı olan 'serdtse' (сердце) kelimesinin somatik yapı ve içeriğinin karşılaştırmalı analizi yapılmaktadır. Çalışmamızın verilerinden derslerde yararlanılacağı gibi çeviri üzerine ders kitaplarının, alıştırma kitaplarının ve deyim sözlüklerinin derlenmesinde pratik sonuçlar ve tavsiyeler de edinilebilir.

Araştırmamızda Ö.A. Aksoy, N.M. Şanskiy, N.V. Basko, D.E. Rozental ve V.V. Vinogradov'un çalışmalarından yararlanarak kendi düşüncelerimizi kaleme almaya çalıştık.

Geçmişten günümüze ulaşan dil ve kültür malzemelerinden biri olan deyimler üzerinde çok çalışmalar yapılmıştır. Fakat somatik deyimler arasında 'kalp' sözcüğü ile kurulan deyimler ve bunların anlam özellikleri ile ilgili karşılaştırmalı olarak Rusça ve Türkçe yeterli sayıda çalışma yapılmamıştır. Dolayısıyla da bu çalışmanın, 'kalp' sözcüğü ile olan somatik deyimlerle ilgili bu boşluğu gidereceğini düşünmekteyiz.

Somatik deyimler, vücut organlarının isimlerinin kullanıldığı deyimsel ifadelerden oluşmaktadır. $\mathrm{Bu}$ deyimlerin başlıca özelliği, söz dizimin de yer alan her bir organ mecazi bir anlama işaret etmesidir. Genel olarak insan veya hayvan davranışının gözlemlerine dayanan mecazi deyimlerdir.

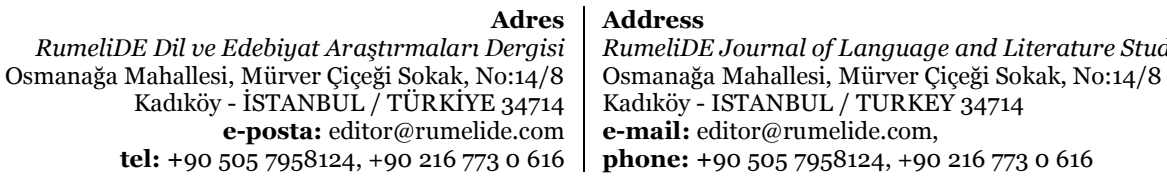


Mecazi doğasıyla dili daha da zengin ve renkli yapan deyimler, insan tecrübesini ve çevremizdeki dünyayı kavramak yollarını yansıtırlar. Bu, insan vücut organları ile oluşan deyimler için daha çok geçerlidir. Çünkü vücut organlarımızı içeren deyimler, insanların duygularıyla sıkı sıkıya bağlıdır (Suleymanova, G.,2018:24).

İnsanın vücut organlarıyla teşkil edilen somatik deyimler, üstlendikleri fonksiyonlara göre milletlerin hayata bakışını, dış dünyayı algılayışını ifade eden farklı anlamları sembolize eder. Somatik deyimlerde yer alan benzetme motiflerinin incelenmesi, dolayısıyla gerçek anlam ile mecazî anlam arasındaki gizli bağın açıklı̆̆a kavuşturulması, dilbilimi araştırmaları için büyük bir önem arz etmektedir (Özkan F., Şadiyeva G., 2003:135).

Deyimlerin oluşumunda somatik birimler kullanılan ifadeler oluşturabilmek için en uygun yollardan biridir. Burada deyimlerin sağladığı faydalar açıkça görülebilir: hafızada kalıcı olaylar gibi önemli vakalar halkın zihninde birikir, ancak bölge, milliyet, kültür gibi farklılıklar nedeniyle bu olaylar da değişiklik görülebilir.

Her dilde somatik deyimsel birimler olarak adlandırılan arkaik ve oldukça geniş bir deyimsel katman vardır.

Somatik deyimin ayırıcı özelliği, dilde çok sayıda karşılığının olmasıdır, bu da, sadece diğer dillerden geçme ile değil aynı zamanda somatik leksemlerin aktarımının evrensel karakterini ve onların deyimsel öbek bileşimindeki dinamiğini ortaya koyan, anlamlarına göre benzer deyimsel ifadelerin ortaya çıkmasına sebep olan kurallarla açıklanır.

Dili etkileyen, kültürün kendine özgülüğünü yansıtan gelenekler ve ritüelleri hakkında konuşmanın zor olduğu farklı ırkların ve halkların temsilcilerinde duyguların ifadesinin ortaya çıkışı somatik deyimsel ögelerin semantiğiyle vurgulanmaktadır.

Her iki dilde de deyimleri çevirirken, deyimin sadece anlamını değil, aynı zamanda onun mecazi anlamını da okuyucuya iletmek çok önemlidir. Eğer şu an Rusçadan Türkçeye ya da tam tersine bir deyimi çevirirsek bu görüntü değişimine yol açar. Araştırdığımız dillerde bazı değişikliklerin olduğunu ve bunun sonucunda deyimsel öbeklerin bir tür dönüşümünün yaşandığını düşünüyoruz. Örneğin; «не стоить и боба» (ne stoit' i boba), «гроша ломаного не стоить» (groşa lomanovo ne stoit') -beş kuruş etmemek, «купить поросенка в мешке» (kupit' porosenka v meşke), «купить кота в мешке» (kupit’ kota v meşke) - gözü kapalı /körü körüne alışveriş yapmak.

Deyimler, çoğunlukla eşdeğeri olmayan ya da tam olarak bir eşdeğere sahip olmayan dil birlikleri olarak sayılmaktadırlar, bu nedenle çoğu durumda, yabancı öğrencinin geldiği ülkede böyle bir ifade olmaması nedeniyle kelimesi kelimesine çevrilemezler.

Deyimleri çevirebilmek, yaratıcı bir yaklaşıma sahip olmayı gerektirir. Deyimlerin sahip olduğu kendi 'mantaliteleri', yani ulusal bir kimlikleri vardır ve bu nedenle deyimleri birebir çevirmek mümkün değildir. Öte yandan, tamamen yeniden yorumlanan deyimler, deyimin ait olduğu halkın düşüncesinin özgünlüğünü yansıtamayacaktır. Deyimlerin çevirisi üzerine yapılan çalışmalarda, eşdeğer oluşturabilecek, dilde köklü bir deyime ya da anlamına yakın uygun bir benzetme kullanılması önerilir.

Rusçadan Türkçeye ya da Türkçeden Rusçaya eşanlamlı deyimlerin gösterildiği sözlüklerin oluşturulması çevirmenin görevini önemli ölçüde kolaylaştırır. Ne yazık ki, deyimlerin büyük

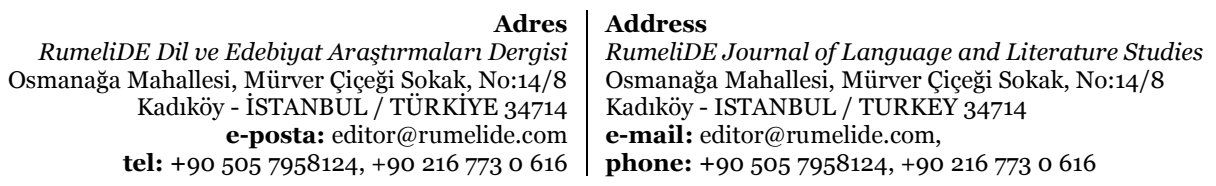


çoğunluğunun tanıtıcı kimliği yoktur. Bu, neologizmlerin (dilde yeni sözcüklerin ortaya çıkması) sürekli ortaya çlkma süreci ile daha da şiddetlenir.

Bu nedenle, yabancı bir dil kullanırken konuşmacı, konuşmasını dinleyicinin doğal konuşmasına mümkün olduğunca dönüştürerek kelimelerin tam çevirisini bilmeye özen göstermelidir. Bu, sözlüksel, dilbilgisel, üslup, fonetik, felsefi, tarihsel, mantıksal ve ülke tarihi bakış açllarından deyim bilgisine katkıda bulunur. Herhangi bir dilde var olan zengin bir deyimsel yapı, konuşmayı inanılmaz derecede güzelleştirir.

'Kalp' bileşeni ile deyimsel öbeklerin yapısının ve içeriğinin karşılaştırmalı bir analizini yaparak bunu göreceğiz. 'Kalp' sözcüğünün seçimi, bu somatizmin yüksek verimlilik ve geniş bir cümle oluşturma potansiyeline sahip olmasından kaynaklanmaktadır. Bu bileşene sahip oldukça fazla deyim vardır ve bunlar yaygın bir kullanıma sahiptir.

Rusçada vücut organ isimleriyle ilgili deyimlerin şekil yönünden bazı değişikliklerin olmasına rağmen anlam yönünden Türkçe ile aynı olduğunu söylemek mümkündür.

Rusçadaki 'duşa' (душа) - ruh somatik belirteci, Türkçede benzer bir anlamı olan kalp- 'serdtse' (сердце) somatik belirtecine eşdeğerdir. Bu dil biriminin tüm çeviri varyasyonlarını ele alacă̆ız:

1. Anatomik bir organ olarak 'kalp'. Örneğin; «сердечный приступ» (serdeçnıy pristup) kalp krizi' уa da «сердце перекачивает кровь» (serdtse perekaçivayet krov') - kalp kan pompaliyor

2. Manevi bir bileşen olarak ruh. Örneğin, «в душе я знаю, что она права» (v duşe уа znayu, çto ona prava) - kalbimde (içten içe) onun haklı olduğunu biliyorum

3. Duygusal bir bileşen olarak aşk, bağlllık. Örneğin; «душа моя» (duşa maya), «любовь моя» (lyubov' тоуа), «сердце моё» (serdtse mоуо) - canım, aşkım, kalbim

4. Coğrafi açıdan 'merkez' anlamı. «в сердце империи» (v serdtse imperii) - imparatorluğun kalbinde/merkezinde

5. Öz, esas, temel anlamında. «в середине сердце» (v seredine serdtse) - kalbin ortasinda, işin özü

İnsan vücudunun iç organlarını adlandırmak için kullanılan söz varlığına ait olan kalp kelimesinin anlamını ele alıp detaylı inceleyelim. 'Kalp' kelimesinin tanımlayıcıları şunlardır: aşk, iyilik, cesaret, içtenlik, açık yüreklilik, sempati, merhamet, arkadaşlık, cömertlik, tutku vb. Manevi özelliklerinin yanı sıra her iki dildeki 'kalp' kelimesi, hayat enerjisini sembolize eder, kişinin karakteri hakkında bilgi verir. Yardım, anlaşma, tavsiye, bilgelik gibi anlamlarına gelmekle birlikte iyi, kötü, mutluluk, önsezi, pişmanlık, korku, acı ve umut gibi kavramları da kapsar.

Araştırmamızı yürütürken Rusçadaki, serdtse (сердце) kelimesiyle oluşturulan en popüler 52 deyimi inceledik. Analiz edilen deyimler için verilen grup isimleri kalp kelimesinin farklı anlamlarına göre oluşturulmuştur. 


\section{Dünyevi ve uhrevi aşk, duyarlılık ve iyilik anlamındaki 'kalp' kelimesi ile oluşturulan deyimler (Olumlu hayat tecrübesi)}

Deyim:

«завоевать сердце» (zavoyevat' serdtse) - kalbini kazanmak, kalpleri (gönülleri) fethetmek

«от всего сердца-от всей души» (ot vsego serdtse-ot vsey duşi) - kalpten (yürekten)

«сердцу не прикажешь» (serdtsu ne prikajeş') - gönül ferman dinlemez

Kalıplaşmış ifade:

«дела сердечные, любовный роман» (dela serdeçnıye, lyubovnıy roman) - gönül işleri, aşk işleri

«привязать сердце» (privyazat' serdtse) - gönül bağı

«мое сердце бьётся для тебя» (moyö serdtse b’yötsya dlya tebya) - kalbim senin için atıyor

«доброе сердце» (dobroye serdtse) - iyi kalpli

«камень свалился с души» (kamen’ svalilsya s duşi) - üzüntüsü hafiflemek, içi rahatlamak, yüreği (kalbi) ferahlamak

«послушай своё сердце» (posluşay svoye serdtse) - kalbinin sesini dinle

«Добро пожаловать в моё сердце» (dobro pojalovat' v moye sertdse) - kalbime hoş geldin

Atasözü:

«путь к сердцу мужчины лежит через его желудок» (put' k serdtsu mujçinı lejit çerez yevo jeludok) - erkeğin kalbine giden yol midesinden geçer

«сердце, которое хоть раз по-настоящему любит, никогда не забывает» / «старая любовь не ржавеет» (serdtse, kotoroye hot' raz po-nastoyaşemu lyübit, nikogda ne zabıvayet) (staraya lyubov ne rjaveyet) - eğer kalp, gerçekten (yürekten) severse bir kere bile onu asla unutmaz

\section{Aforizma:}

«роза говорит о любви без звука, языком известным только сердцу» (roza govorit o lyubvi bez zvuka, yazıkom izvestnım tol'ko serdtsu) - gül, aşkı söz olmadan kalbin anlayacağı dilde anlatır.

\section{Așkın acı olduğu (Olumsuz hayat tecrübesi) anlamında 'kalp'}

Deyim:

«разбить чьё-то сердце» (razbit’ çiyo to serdtse) - birinin kalbini kırmak

«душа в пятки ушла» (duşa v pyatki uşla) - yüreği ağzına gelmek, ödü kopmak

«душа обливается кровью» (duşa oblivayetsya krov'yu) - yüreği kan ağlamak

«душа разрывается на части» (duşa razrıvayetsya na çasti) - yüreği parça parça oluyor

«сердце кровью обливается» (serdtse krovyu oblivayetsysa) - yüreği szzlamak

«с тяжёлым сердцем» (s tyajölım serdtsem) - üzülerek, kalbi burkularak

«каменное сердце» (kamennoye serdtse) - taş kalpli

\footnotetext{
Adres | Address

RumeliDE Dil ve Edebiyat Arașttrmaları Dergisi Osmanağa Mahallesi, Mürver Ciceği Sokak, No:14/8 Kadıköy - İSTANBUL / TÜRKIYE 34714 e-posta: editor@rumelide.com

RumeliDE Journal of Language and Literature Studies Osmanağa Mahallesi, Mürver Çiçeği Sokak, No:14/8

Kadıköy - ISTANBUL / TURKEY 34714

e-mail: editor@rumelide.com

tel: +90 505 7958124, +902167730616 phone: +90 505 7958124, +90 2167730616
} 
Atasözü:

«с глаз долой - из сердца вон» (s glaz doloy - iz serdtse von) - gözden irak olan gönülden de irak olur

«камень на сердце» (kamen' na serdtse) - kalbi buruk bir şekilde, yüreğine taş basmak

«открыть сердце» (otkrıt’ serdtse) - içini dökmek, kalbini açmak

Kalıplaşmış ifade:

«одно сердце страдает, другое не знает» (odno serdtse stradayet, drugoye ne znayet) -bir kalp acı çeker diğerinin haberi olmaz

«сердце разрывается на части» (serdtse razrıvayetsya na çasti) - yüreği parçalanmak

\section{Aforizma:}

«не заживет рана в сердце» (ne zajivayet rana v serdtse) - gönül yarası geçmez

\section{Hayat, yaşam gücü, dilek anlamında 'kalp'}

\section{Aforizma:}

«проснитесь на рассвете с окрыленным сердцем и воздайте благодарность за еще один день любви» (prosnites' na rassvete s okrılennım serdtsem i vozdayte blagodarnost' za yeşo odin den' lyubvi) - gün doğumunda coşkulu bir kalple uyanın ve sevgiyle geçireceğiniz bir gün için daha şükredin

Deyim:

«духу не хватает» (duhu ne hvatayet) - yüreği / cesareti olmamak

«делать так, как сердце велит» (delat' tak, kak serdtse velit) - kalbinin götürdüğü yere gitmek

«слушай своё сердце» (sluşay svoyo serdtse) kalbinin sesini dinle

«это мнение найдёт отклик в сердцах всех» (eto mneniye naydyöt otklik v serdtsah vseh) -bu fikir herkesin gönlünde taht kuracak

«чуять сердцем» (çuyat' serdtsem) - içine doğmak,

«душа не на месте» (duşa ne na meste) - huzursuz olmak, içi rahat etmemek

\section{Kişinin karakteri, mizacı anlamında 'kalp'}

Kalıplaşmış ifade:

«с открытым сердцем» (s otkritıyem serdtsem) - tüm kalbimle

«душа нараспашку» (duşa naraspaşku) - içi dışı bir

«чистосердечный» (çistoserdeçnı) - açık yüreklilik

«иметь золотое сердце» (imet' zolotoye serdtse) - altın kalpli

«иметь доброе сердце» (imet’ dobroye serdtse) - iyi kalpli

«мягкосердечный человек» (myakoserdeçnıy çelovek) - yufka yürekli

\footnotetext{
Adres | Address

RumeliDE Dil ve Edebiyat Araşttrmalar Dergisi Osmanağa Mahallesi, Mürver Çiçeği Sokak, No:14/8 Kadıköy - İSTANBUL / TÜRKIYE 34714 e-posta: editor@rumelide.com tel: +90 505 7958124, +90 2167730616

RumeliDE Journal of Language and Literature Studies Osmanağa Mahallesi, Mürver Çiçeği Sokak, No:14/8

Kadıköy - ISTANBUL / TURKEY 34714

e-mail: editor@rumelide.com,

phone: +90 505 7958124, +90 2167730616
} 


\section{Cömertlik, nezaket anlamında 'kalp'}

Deyim:

«сколько душе угодно» (skol'ko duşe ugodno) - canının istediği kadar

«от души» (ot duşi) - içten, yürekten

\section{Gerçek/ hakikat anlamında 'kalp'}

Deyim:

«в глубине души» (v glubine duşi) - can-ı gönülden

«сердце / душа не лежит» (serdtse / duşa ne lejit) - canı çekmiyor, istek duymuyor

«скрепя сердце» (skrepya serdtse) - kalbi mühürleyerek, isteksiz

«принимать близко к сердцу» (pirinimat blizko k serdtsu) - kalbe yakın almak, evham etme

Aforizma:

«для того, чтобы изменить умы, надо сначала изменить сердца» (dlya tovo, ştobı izmenit' umı, nado snaçala izmenit' serdtsa) - fikri değiştirmek için önce kalbi değiştirmelisiniz

Kalıplaşmış ifade:

«положить руку на сердце» (polojit ruku na serdtse) - elini kalbine (vicdanına, yüreğine) koymak

\section{Ruh hali, duygu durumu, keyif anlamında 'kalp'}

Deyim:

«по душе» (ро duşe) - gönlüne göre

«как масло по сердцу» (kak maslo po serdtsu) - yürekten sevinmek

\section{Korku anlamında 'kalp'}

Deyim:

«сердце в пятки ушло» (serdtse v pyatki uşlo) - yüreği ağzına gelmek

«сердце чуть не выскочило из груди» (serdtse çut' ne vıskoçilo iz grudi) -kalbi yerinden oynadı

\section{Cesaret anlamında 'kalp'}

Deyim:

«собираться с духом» (sobirat'sya s duhom) - cesaretini toplamak

\section{Deyimsel ifadeler}

Deyimler

Atasözü

Kalıplaşmış ifadeler

Aforizma

\section{Sayısı}

27

5

16

4
RumeliDE Dil ve Edebiyat Araşttrmaları Dergisi Osmanağa Mahallesi, Mürver CCiçeği Sokak, No:14/8 Kadıköy - İSTANBUL / TÜRKIYE 34714 e-posta: editor@rumelide.com tel: +90 505 7958124, +90 2167730616
Address

RumeliDE Journal of Language and Literature Studies Osmanağa Mahallesi, Mürver Çiçeği Sokak, No:14/8

Kadıköy - ISTANBUL / TURKEY 34714

e-mail: editor@rumelide.com,

phone: +90 505 7958124, +90 2167730616 


\section{Sonuç}

Analizimiz, Türkçedeki 'kalp' ve Rusçadaki 'serdtse' (сердце) somatik belirteçlerinin temel olarak samimiyet, sevgi ve acı gibi hislerin aracı olduğunu göstermiştir. Somatik deyimler genellikle bir kişinin iç dünyasını ifade etmek için kullanılır. Ayrıca her iki dil için kalp kelimesinin duyguları, nezaketi, sevgiyi, sevinci, coşkuyu, aşkı, hüznü ve üzüntüyü sembolize ettiğini de unutmamak gerekir. Araştırmanın sonucunda Rusçada daha çok 'duşa' (душа) ruh kelimesi, Türkçede ise 'kalp' kelimesi kullanıldığını, Türkçedeki 'kalp' sözcüğünün genel olarak Rusçadaki 'duşa' (душа)- ruh kelimesinin eşdeğeri olarak kullanıldığını görmekteyiz.

Rus ve Türk halklarının farklı düşünme biçimlerine rağmen bu deyimsel ifadelerin önemli bir benzerlik gösterdiğini ortaya koyduk.

Türkçe ve Rusçadaki ‘kalp’ sözcüğü ile oluşturulan somatik deyimlerin büyük kısmı anlam ve görünüş açısından uyuşmaktadır, zira sözvarlığının bu katmanı yaygın kullanıma sahiptir ve o dili konuşan hakların milli ve tarihi özellikleriyle ilişkili değildir ki, bu duruma diğer temalara ait kelime gruplarında oldukça nadir rastlanır.

Somatik terimbilimin deyim sisteminde özel bir yer kapladığını belirterek, beden yoluyla edinilen ve somatik terimlerle sabitlenen bilgi, insanın zihinsel, ruhsal ve fiziksel birliğini ortaya koymaktadır.

Deyimsel birimler, Dilbilim içerisinde geniş ve üretken gruplardan biridir ve yapılan çok sayıda bilimsel çalışmaya rağmen, daha ayrıntılı bir çalışma gerektirir.

\section{Kaynakça}

Aksan, D. (2015). Her yönüyle dil (Ana Çizgileriyle Dilbilim). Ankara: Türk Dil Kurumu.

Akkök, E. A. (2009). Yabancı dilde deyimlerin öğretimi, Dil Eğitimi ve Araştırmaları Dergisi, Sayı: 143 Ocak-Şubat-Mart 2009, Ankara Üniversitesi Sosyal Bilimler Enstitüsü, Ankara.

Aksoy, Ö. A. (1995). Atasözleri ve deyimler sözlüğü I-, İstanbul: İnkılap Kitabevi.

Basko, N.V. (2002). Frazeologizmı v russkoy reçi, Nauka.

Barın, E (2004). Yabancılara Türkçe öğretiminde ilkeler, Türkiyat Araştırmaları, Hacettepe Üniversitesi Türkiyat Araştırmaları Enstitüsü, Yıl: l.

Çelik,Y. (2017). Türkiye Türkçesinde duyu organlarıyla kurulan deyimler, Uluslararası Sosyal Araştırmalar Dergisi, Sayı 50

Dalak Erten, H. D. (2017). Yabancı dil olarak Türkçe öğretiminde iletişimsel yaklaşımın deyim öğretiminde başarıya etkisi, Hacettepe Üniversitesi Türkiyat Araştırmaları Enstitüsü, Türkiyat Araştırmaları Anabilim Dalı Yabancı Dil Olarak Türkçe Öğretimi Yüksek Lisans Programı, Yüksek Lisans Tezi, Ankara.

Güngör, N. (1991). Kültür-Eğitim-Dil Üzerine Görüşleri ile Z.Fahri Fındıkoğlu. Ankara: Kültür Bakanlığı.

Hengirmen, M. (2007). Atasözleri ve deyimler sözlüğü 2. Ankara: Engin.

Humboldt,V. (1984) İzbrannıye trudı po yazıkoznaniyu. Moskova: Progress.

Özkan, F., Şadiyeva G. (2003). Somatik deyimler, Bilig Türk Dünyası Sosyal Bilimler Dergisi, Sayı 24

Rozental, D.E. (1979). Sovremennıy russkiy yazık, Leksika i frazeologiya, Moskova: Vısşaya şkola.

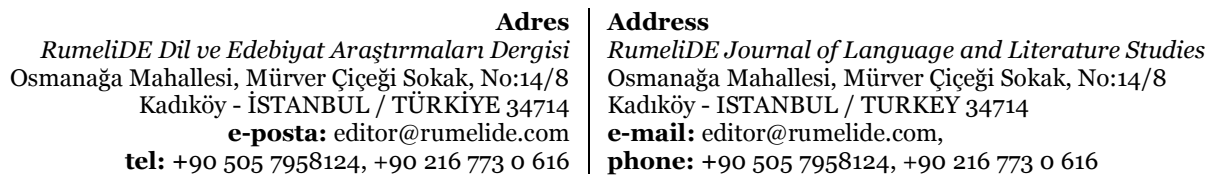


Suleymanova, G. (2018). Oğuz grubu Türk lehçelerinde organ isimleri ile yapılan deyimler, Gazi Üniversitesi Sosyal Bilimler Enstitüsü,Çağdaş Türk Lehçeleri Anabilim Dalı, Doktora Tezi, Ankara

Şanski, N.M. (1985). Frazeologiya sovremennogo russkogo yazıka, M, Vış̧aya Şkola.

Vinogradov, V.V. (1977). Ob osnovnıh tipah frazeologiçeskih ediniçh v russkom yazıke,M. 